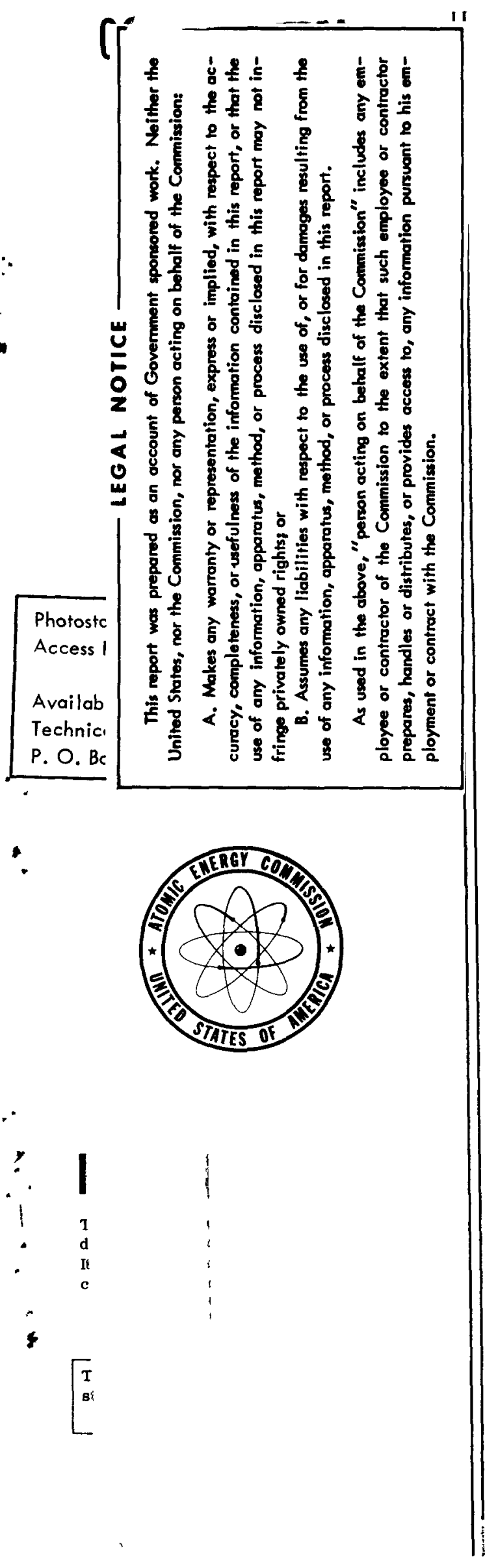

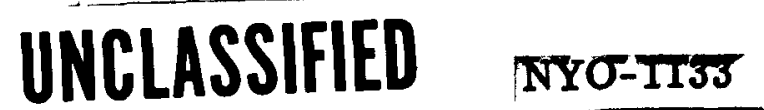

\section{ATMOIZATION METHOD OF MAKING URANIUM POWDER}

By Henry H. Hausner and Herman Mansfield

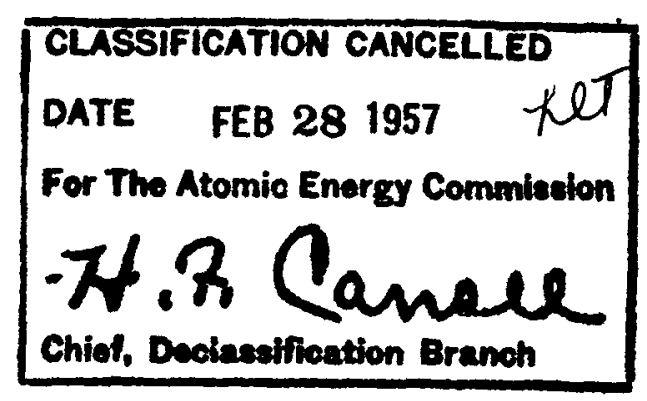

Aug. 7, 1950

Sylvania Electric Products, Inc. Bayside, N. Y.

This document is PUBLICLY RELEASABLE ORO Review Teain Authorizing Official Date $11-9-2010$

UNITED STATES ATOMIC ENERGY COMMISSION Technical Information Service, Oak Ridge, Tennessee ro.1

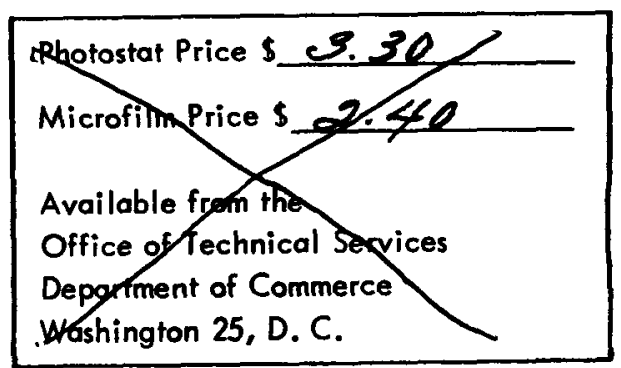




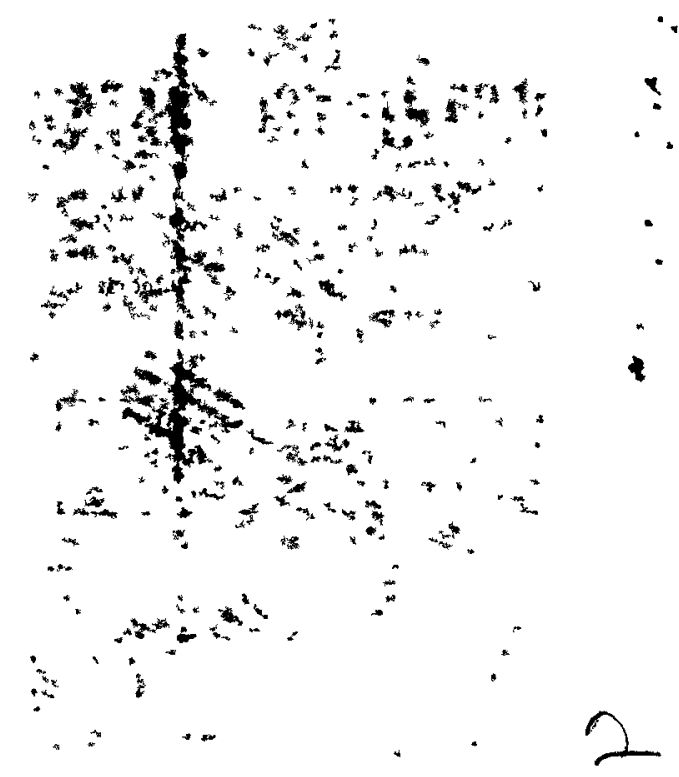




\section{DISCLAIMER}

This report was prepared as an account of work sponsored by an agency of the United States Government. Neither the United States Government nor any agency Thereof, nor any of their employees, makes any warranty, express or implied, or assumes any legal liability or responsibility for the accuracy, completeness, or usefulness of any information, apparatus, product, or process disclosed, or represents that its use would not infringe privately owned rights. Reference herein to any specific commercial product, process, or service by trade name, trademark, manufacturer, or otherwise does not necessarily constitute or imply its endorsement, recommendation, or favoring by the United States Government or any agency thereof. The views and opinions of authors expressed herein do not necessarily state or reflect those of the United States Government or any agency thereof. 


\section{DISCLAIMER}

Portions of this document may be illegible in electronic image products. Images are produced from the best available original document. 

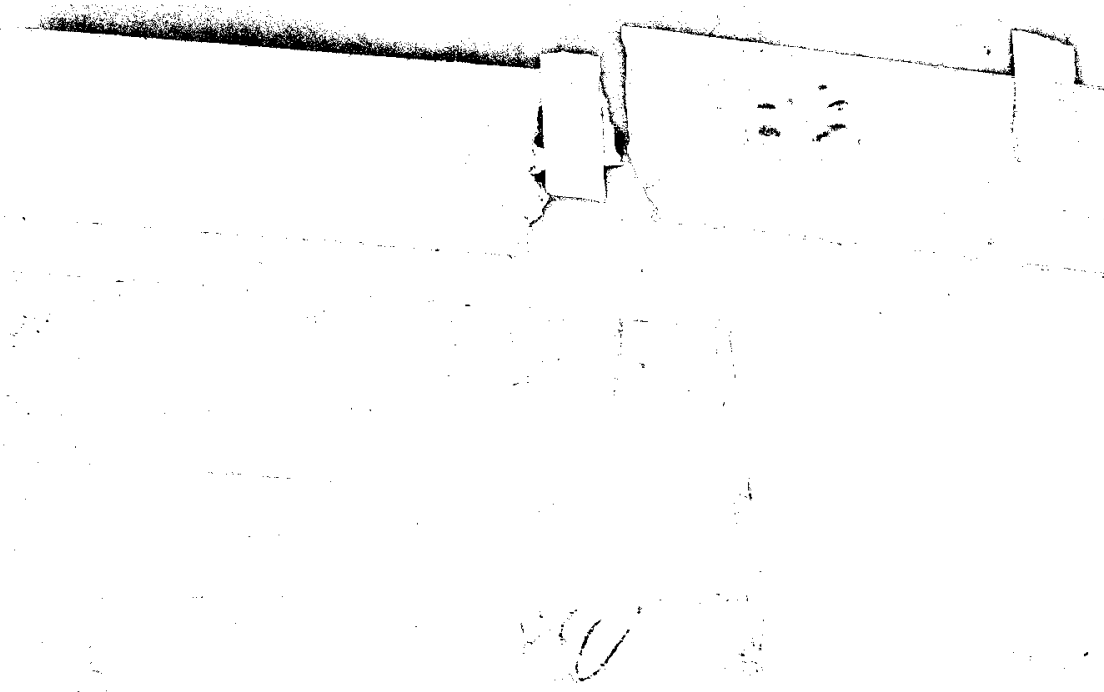

\section{ABSTRACT}

Atomized uranium powder was produced by forming an electric are between two uranium electrodes in an inert atmosphere and sending a high velocity stream of inert gas through the are.

Uranium particles obtained by this method: were of spherical shape: smaller particles contained mostly small grains, and largex particles were characterized by larger grains. The particles were ductile and could be hot-pressed to a compact of high density。

The temporary equipment used for these preliminary tests on atomization was not adequate to control particle size. The report $_{3}$ however, includes suggestions for the production of atomized uranium powder of controllable quality. 
I. INTRODUCTION

Uranium powder produced in the conventional manner by the decomposition of uranium hydride is characterized by extremeiy omall particle. size. Flectron microscopic investigation of such powder, revealed a large percentage of particles in the 0.1 to 0.5 micron range. The determination of particle size distribution in this range is, of course, extremely difficult and of questionable accuracy. This small penticle size is undesirable, because of the large total surface area that results in rapid oxidation of the powder as weil as of the compacts pressed therefrom. In addition, conventional pressing and sirterirg of sampats made from this powder yields a material of fairly Low density, and no means have beer found for controlling the perosity of the sintered ecmpact Testo aimed at variation in partisie sizs of the uranium hydroide ar the decomposed. hydride Indifsated that it was impossible to obtain larger pantieles.

Sirce the atomiztion method seems to have possibilities of producing a powder of langer and contrcliable pariole size, with a relatively smalI surface area and thereforo less oxidation, preiiminary attempts were made to atomize uranium.

\section{ATOMIZATION OF URANIUM}

Atsuixation ¿s generally 3womplished by forsing molten metai through an orifice. and by breaking up the stream of metal by a stream of air, an inertigas, water vapors a rotating dise, or simply by al lowing it to fali into a liquid. Uranium, howerer, because of its extremely reactive nature is not. readily adaptable to any of the abore general methods. An attempt was made, therefore, to prepare uranium powder by forming an are between two uranium electrodes in an inert atmosphere and sending a high velocity stream of inert gas through the arca. Uniike the method of meIting were the molten metal is in contact with the crucible, this method of atomization has the advantage of producing small amounts of the metal at elevated temperature whlch have no other contact than with the inert gas: the method is based on the design principie of some metal spray guns.

In order to study the feasibility of the atomization process for uranium, preliminary experiments were made whereby two uranium electrodes were inserted in a dry box filled with argon (99.6\% purity) or helium (99.9\% purity). One electrode, a uranium rod cne inch in diameter and six inches long was held stationary, and the other uranium electrode (wires varying from 0.09 to $0.25^{\mathrm{m}}$ in 


\section{ATOMIZATION OF URANIUM (cont ${ }^{8} \mathrm{~d}$ )}

diameter) was moved by hand. The direction of electrode feed was varied: some runs were made with horizontally arranged electrodes and other wuns were made whth electrodes arranged in a vertical plane. The power sourse was motor generator (100 amp. maximum on the d-c side). A high-velocity stream of gas (argon or helium, approximately $375-400 \mathrm{cu}, \mathrm{ft}_{0} / \mathrm{hr}_{\mathrm{o}}$ ) was sent through a nozzle orifice of approximately $1 / 32^{\prime \prime}$ in width and about $3 / 8^{\prime \prime}$ in length and was directed into the center of the arc. (It should be noted that the stream of gas covered not only the metal vapor in the arce, but also the moiten material on the face of the electrode). This high velocity stream of gas broke the molten and vaporous material into particles and transported them over horizontal distances cf approximateiy 12-15". The particles were collected in a receptable which was held in the line of particle flow. During the course of several runs, the dew point of the atmosphere and the dry box dropped radicaliy from approximately minus $55-65^{\circ} \mathrm{C}$ to minus $30-35^{\circ} \mathrm{C}$, probably caused by the surface of the walls giving off moisture as the dry box temperature increased from the $\mathrm{arc}_{3}$ the temperature of which was estimated at over $3000^{\circ} \mathrm{C}$.

It seems that the method of atomization is promising, however, it is obvious that many variables must be controlled in order to obtain the optimum yield of desired powder. Among them are voltage, current, and current, densit $\mathrm{y}_{9}$ size and shape of the uranium electrodes, the speed of wire movement, the direction of approach of electrodes (horizontally or vertical), the gas atmosphere, the pressure and velocity of the gas, and the shape and arrangement of the jet.

\section{CHARACTERISTICS OF ATOMIZED URANIUM}

The uranium particles obtained by this method can be characterized as follows:

1. Most of the particles obtained by this method approached the spherical shape.

2. The particle sizes varied between <44 and 2000 microns, with a great predominance of the large particles.

3. Most of the particles were covered with an oxide film apparentiy caused by the inadequacies of the equipment used. It was possible to remove the oxide film by cleaning the powd in nitric acid.
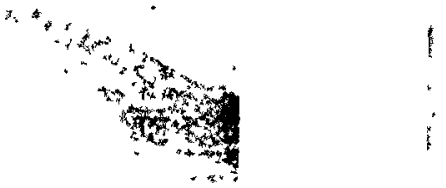
III. CHARACTERISTICS OF ATOMIZED URANIUM (cont'd)

4. The high ductility of this powder was shown by hammering the particles to thin flat dises and by sompacting in a die.

The following observations were made on the particles obtained during the preliminary runs:

A. Particie Size and Grain Structure

The typical screen analysis of the powder of one of the runs in argon is show in Table $I$.

TABLE I

\begin{tabular}{|c|c|}
\hline Mesh Size & Peroent by Weight \\
\hline & \\
$-10+20$ & 17.3 \\
$-20+40$ & 55.4 \\
$-40+60$ & 19.5 \\
$-60+80$ & 5.3 \\
$-80+100$ & 1.4 \\
$-100+140$ & 0.4 \\
$-140+325$ & 0.4 \\
-325 & 0.2 \\
\hline
\end{tabular}

Particles of the sizes above +40 mesh are too large for powder metsllurgy purposes, although they might be useful for other applications. Howerer, experience with other metals, especially copper, prepared by similar methods of atomization, showed that the particle size can be widely controlled by the variables mentioned above especially the curreent density, the speed of electrodes and the gas flow. Although these variables could not be properiy studied with the equipment described above there is every rasison to expect finer uranium powder when produced proper conditions.

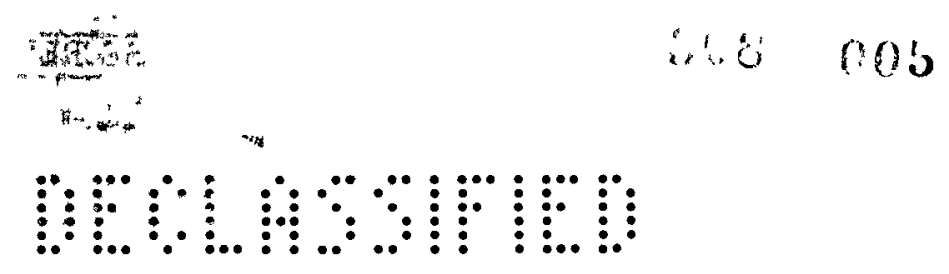


III. - CHARACTERTSTICS OF ATOMTZED URANIUM (cont ${ }^{2} d$ )

Nost of the particles were of spherical shape as shown in Figs. $I$ and 3. From these figures, and from the metallographic investigations of many other particles, the grain size of the particles appeared to be correlated to a certain extent to the particle size and to the type of gas atmosphere used for breaking the molten metal. In general, but not always, smaller particles contained smaller grains and larger particles contained larger grains. It seems further that particles obtained in argon atmosphere contain larger grains than particles of similar size obtained in an atmosphere of helium. These observations can be explained in the following way smaller particles cool much faster than large particles. Particles formed and cooled in helium cool much faster than those formed and cooled in argon, on cocunt of the greater heat conductivity of helium compared with that of argon. The cooling time affects the grain size - fast cooling is characterized by fine grains and slow sooling by larger grains, as shown in Figs, $I_{g} 2_{2}$ and 3 . The speed of cooling and the cooling medium alse affect the rate of particle oxidation.

B. Purity of Atomized Powder

One of the most important considerations in evaluating the usefulness of atomized uranium powder is the purity of the material. The atomization process practically excludes additions of metallic impurities even at runs made with the imperfect equipment used for these preIiminary tests. Speetrographic investigations actuaily did not reveal any differences in the metallic impurities of the atomized powder compared with the electrodes from wich the porder was obtained.

Gas anolyses, however, revealed fairly large differenees: especially differenes in the oxygen content between the atomized powder and the uranium electrodes. It was obo served that most of the particles having a black coating could be cleaned by etching with diluted nitric acld and by drying with acetone. The powder particles shows a typcial metallic gray surface after cleaning. Table II shows the hydrogen, oxygen and nitrogen content of the cast uranium from which the electrods were made, of the electrodes and of the pows of several runs before and atter acld clening. The data show that a large amount 
III. CHARACTERISTICS OF ATOMIZED URANIUM (cont'd)

of the oxygen content is on the surface of the particles and can be removed by acid cleaning. An analysis of samples \#7 and \#8 showed that the oxygen content is a function of the particle size and that finer partioles contain relatively more oxygen than coarser particles. In order to evaluate the gas analysis of the particles, one has to consider that the particles were produced in an inadequate and imperfect apparatus and under crude conditions. The high amount of oxygen cannot be attributed to the process or to the gas atmosphere in which the process occurred but rather is caused by the water vapor formed in the dry box during the runs.

\section{TABLE II}

\begin{tabular}{|c|c|c|c|c|}
\hline $\begin{array}{l}\text { Sample } \\
\text { No. }\end{array}$ & Material Tested & $\% \mathrm{H}_{2}$ & $\% \mathrm{O}_{2}$ & $\% \mathrm{~N}_{2}$ \\
\hline 1 & $\begin{array}{l}\text { Cast uranium frem which the electrodes } \\
\text { are made. }\end{array}$ & 0.003 & 0.020 & 0.004 \\
\hline 2 & Wire electrode $0.09 "$ diameter, clean & 0.001 & 0.026 & 0.005 \\
\hline 3 & $\begin{array}{l}\text { Run \#4 powder, atomized in argon } \\
\text { (dew pcint }-40^{\circ} \mathrm{C} \text { ) before, cleaning }\end{array}$ & 0.002 & 0.108 & 0.013 \\
\hline 4 & Run \#L powder, after acid cleaning & $<0.001$ & 0.070 & 0.012 \\
\hline 5 & $\begin{array}{l}\text { Run \#5 powder, atomized in helium } \\
\text { (dew point }-65^{\circ} \mathrm{C} \text { ) before cleaning }\end{array}$ & 0.001 & 0.090 & 0.009 \\
\hline 6 & Run \#5 powder, after cleaning & 0.001 & 0.031 & 0.006 \\
\hline 7 & $\begin{array}{l}\text { Run \#8 powder, atomized in argon } \\
\text { (dew point }-35^{\circ} \mathrm{C} \text { ) particle size } \\
-60+80 \text { mesh, after cleaning }\end{array}$ & 0.003 & 0.125 & 0.041 \\
\hline 8 & $\begin{array}{l}\text { Rur \#8 powder, particle size } \\
-10+20 \text { mesh, after cleaning }\end{array}$ & 0.001 & 0.079 & 0.009 \\
\hline
\end{tabular}


III. CHARACTERISTICS OF ATOMIZED URAAIUM (cont'd)

C. Hardness and Duetility

Further evaluation of the atomized uranium powder was made on the basis of hardness. The hardness of the powder particles is, in general, higher than that of the uranium electrodes from which they were atomized. The Vicker.'s hardness of the particles atomized in argon was between $365-430 \mathrm{dph}$, whereas the hardness of the uranium electrode was approximately $240 \mathrm{dph}$.

Ductility tests were made in two ways: (a) by hammering individual particles and (b) by pressing a few grams in a die similar to that used for the compacting procedure in powder metallurgy. Hammering showed that the spherical particles flatten without cracking, which indicates a fairly high degree of ductility. The particles were pressed in a double-action die of $3 / 8^{\prime \prime}$ diameter at 50 tsi. The pressed density of the compact was $14 \mathrm{~g} / 00$, wich is higher than the density of urarium powder made by the hydride method and compa ated under similar conditions. This, too, indicates the flattening of the particles during pressing and the high ductility of this powder.

D. Sintering of Atomized Powder

The rate of sintering is a function of the particles and void sizes in the compact and a very low sinter ing rate could, therefore, be expected with compacts made from the large atomized uranium powder particles. As described above, the powder was pressed at 50 tsi and compacted to a density of $14 \mathrm{~g} / \mathrm{cc}_{\text {. During }}$ sintering in vacuum $\left(0.01\right.$ micron) at $1090^{\circ} \mathrm{C}$ for three hours, the compact expanded and the density decreased to $11.5 \mathrm{~g} / \mathrm{co}_{0}$. The decrease in density was probably due to surface oxidation and the low density was to be expected on account of the large pores in the pressed compact and on account of the relatively short sintering time, However, even during this short time, perfect diffusion bonds between the particles, and also bridges between the particles were formed, as shown in Figs. 4 and 5. Tun sintered compact was subom stantially stronger than thy yomact in the as-pressed state. Another specimen, presed in a single action die at 70 tsi had a grededesply of $14.8 \mathrm{~g} / \mathrm{cc}$. Sintering 
III. CHARACTERISTICS OF ATOMIZED URANIUM (cont'd

this compact in vacuum at $1100^{\circ} \mathrm{C}$ for six hours produced a similar effect as on the above described specimen, i.e., growth of dimensions, and consequent production of density to $13.85 \mathrm{~g} / \mathrm{cc}$. The grains of this compact grew during sintering, but to a lesser degree than in similar compacts made from decomposed uranium hydride powder. Sintered compacts of similar low density made from the extremely fine decomposed hydride powder could not be handled in air but burmed immodiately. The sintered compact made from the coarse atomized uranium particles could be handled in air without any danger of burming.

Hot-pressing the atomized powder in the alpha range (25 tsi at $600^{\circ} \mathrm{C}$ for 15 minutes) yielded a compact having a density of $18.4 \mathrm{~g} / \mathrm{cc}$ which indicates the high plasticity of the atomized uranium porder at $600^{\circ} \mathrm{C}$ (Fig. 6)。 The hot-pressed compact was practically free of pores. The grains were of medium size similar to the grain size of the original particles. The hotpressed compact did not have any considerable strength; it seems that the short exposure to a fairly low temperature did not permit the formation of any diffusion bonds.

In the trend of some of our studies concerning the development of compound materials consisting of a metallic matrix and discrete particles of uranium uniformly distributed in the matrix, experiments were made with the spherical atomized powder particles inserted in a solid matrix of fine-grained uranium. For the development of this compound material a small amount of large atomized uranium particles was mixed with the fine uranium powder made by the decomposition of uranium hydride and the mixture was hot pressed in the alpha range at $25 \mathrm{tsi}, 550^{\circ} \mathrm{C}$ for 15 minutes. The density of the hot-pressed uranium mixture was again $18.4 \mathrm{~g} / \mathrm{cc}$ and the compound material exhibited considerable strength. Fig. 7 shows a structure of this compound material and the complete separation of the particles made by atomization from the matrix made from decomposed uranium hydride. The grain structure of the spherical particles did not change during hot pressing.
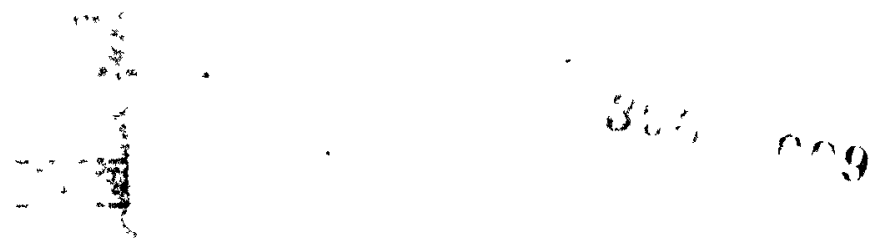
IV。 FURTHER DEVEIOPMENTS

In order to obtain a controllable product, the process must be done automatically and in an inert atmosphere of high purity. Before designing the pilot plant for the atomization of uranium, further studies are to be made which should include the following:

1. Comparisons of helium arid argon as atomizing media regarding their effect on particle size, grain size within the particle, and other properties.

2. The effect of wire diameter and speed of wire movement, voltage variations and various current densities, varying jet pressures, and optimm collection of particles should be determined. These variables should be evaluated on the basis of their influence on particle shape, particle size and particle size distribution, grain structure, stability of grains within the particles at elevated temperatures, oxygen content, hardness, ductility, and compressibility, as well as their sintering characteristics.

The equipment necessary to make the studies should include:

1. A mechanism for moving two uranium wire electrodes which permit the use of various diameters of wire at various speeds of approach.

2. A dry box with optimum dimensions, with tight inlets for wire electrodes, power, etc., and with a pressure release valve to prevent over-pressure.

3. A high pressure gas purification train to be used to purify both the atmosphere in the dry box and the high-speed gas for atomization.

4. A device for collection of the powder which permits fast cooling of the particles thus preventing the formation of agglomerates.

The results described here show that uranium powder can be manufactured by atomization and that modifications of the described method will result in usable particles of controllable sizes.

Any suggestions for the enplication of the atomized uranium powder for purposes other then pher metwary will be welcomed by the authors of this report.

HHH:MS

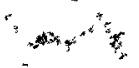




\section{3}

cherm

NIO 1133

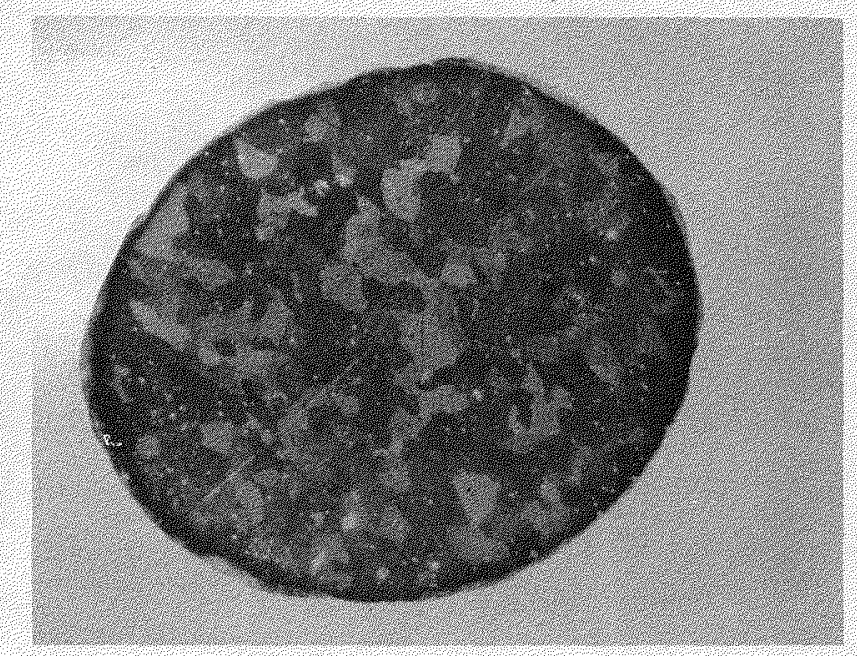

Fig. 1

Plate 3361
Particle size -40 tolarized light $200 \mathrm{x}$

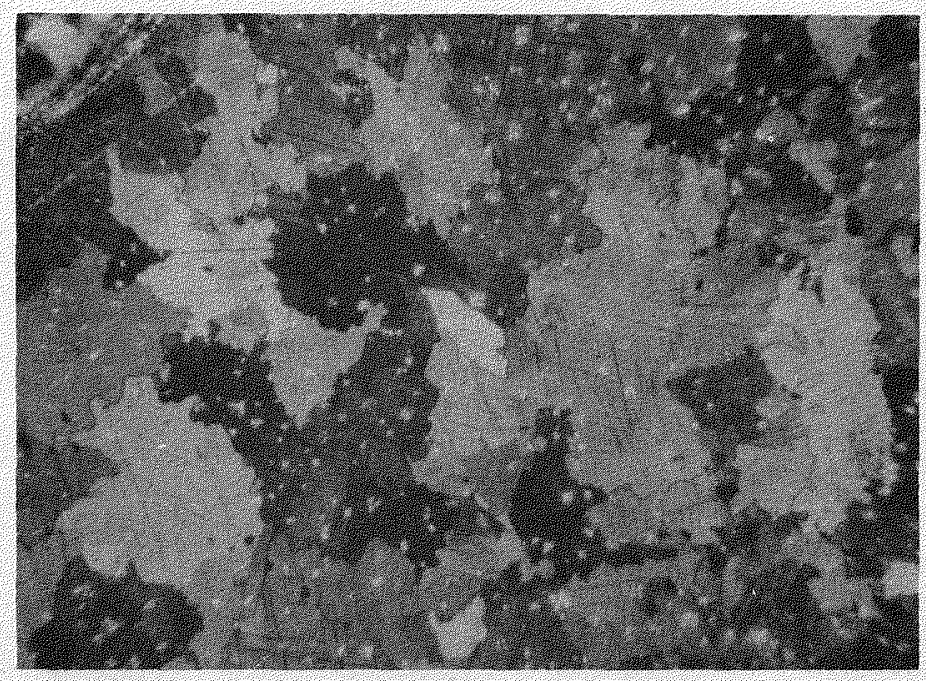
Plate 3360 Fig. 2 Polarized light $200 \mathrm{x}$
Particle size t40 mesh


NYO-I新3

14

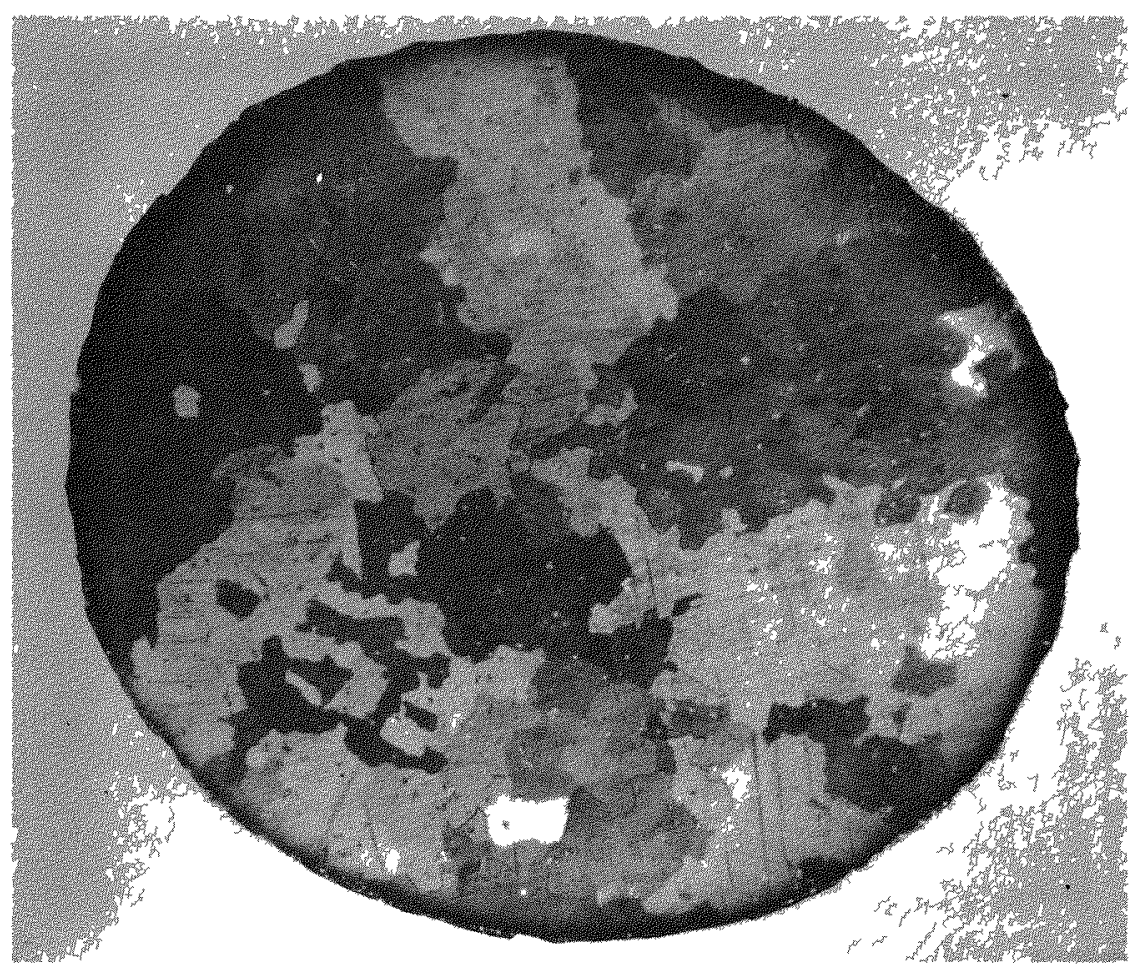

Fig. 3

Plate 3504

Polarized light 200x

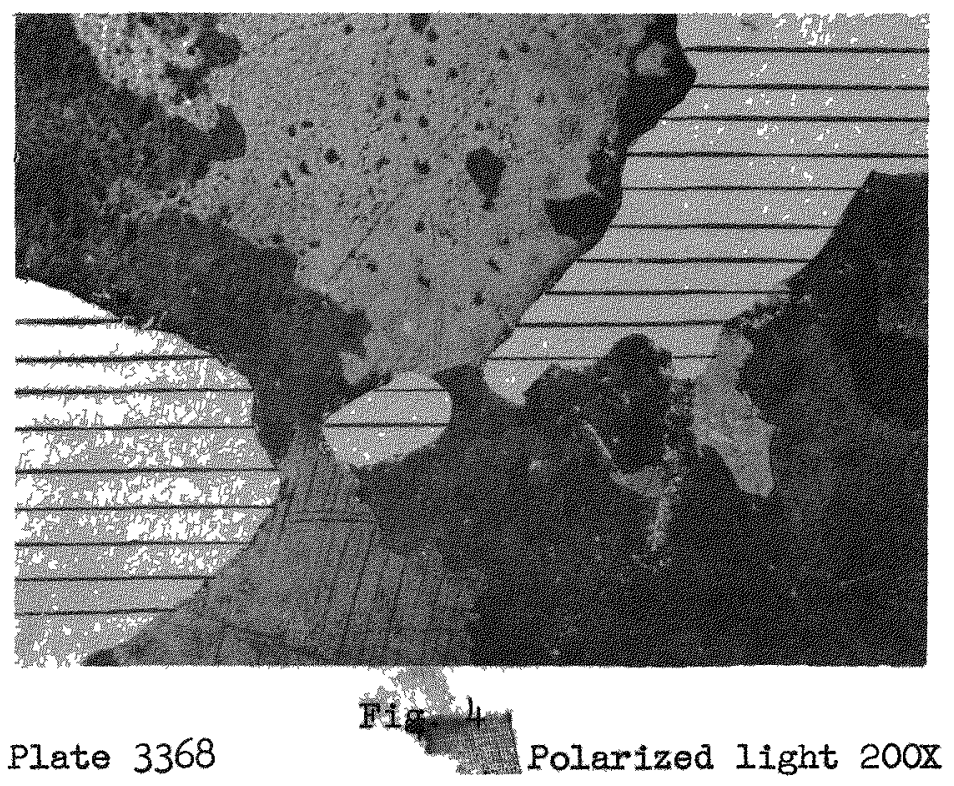

012

萝 


\section{5}

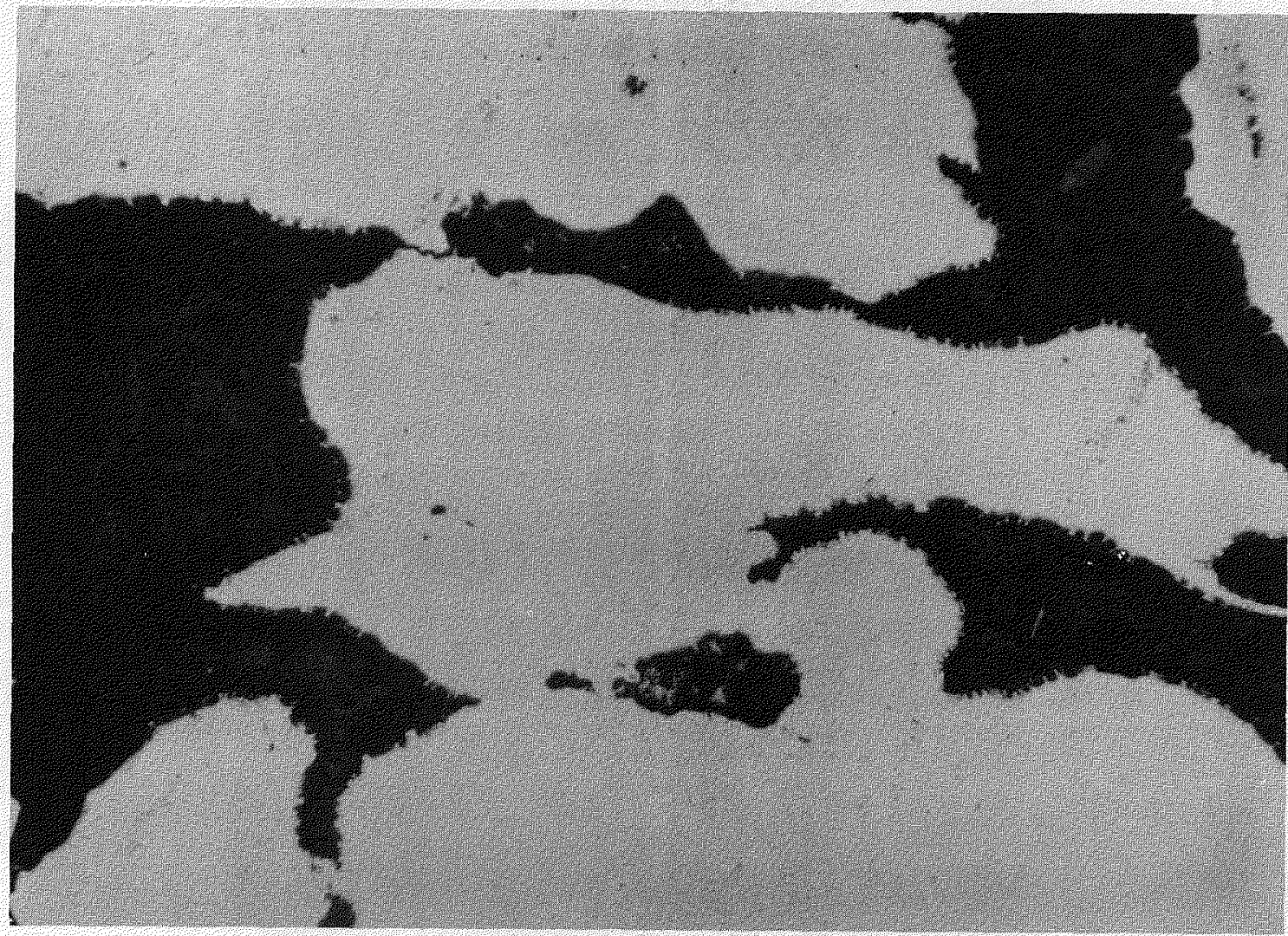

Plate 3364

Fig. 5

Bright Field 200x 


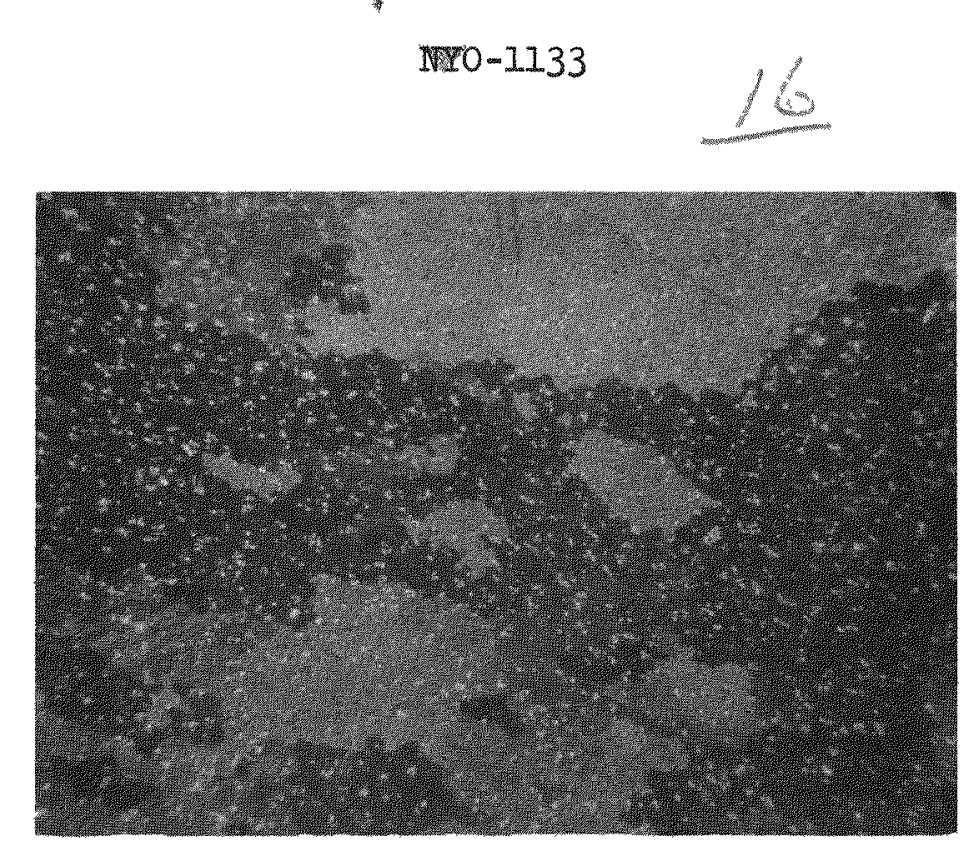

Fig. 6

Plate $3798 \quad$ Polarized light 200X Uranium powder formed by atomization, hot pressed at $25 \mathrm{tsi}, 600^{\circ} \mathrm{C}$, for 15 minutes in vacuum.

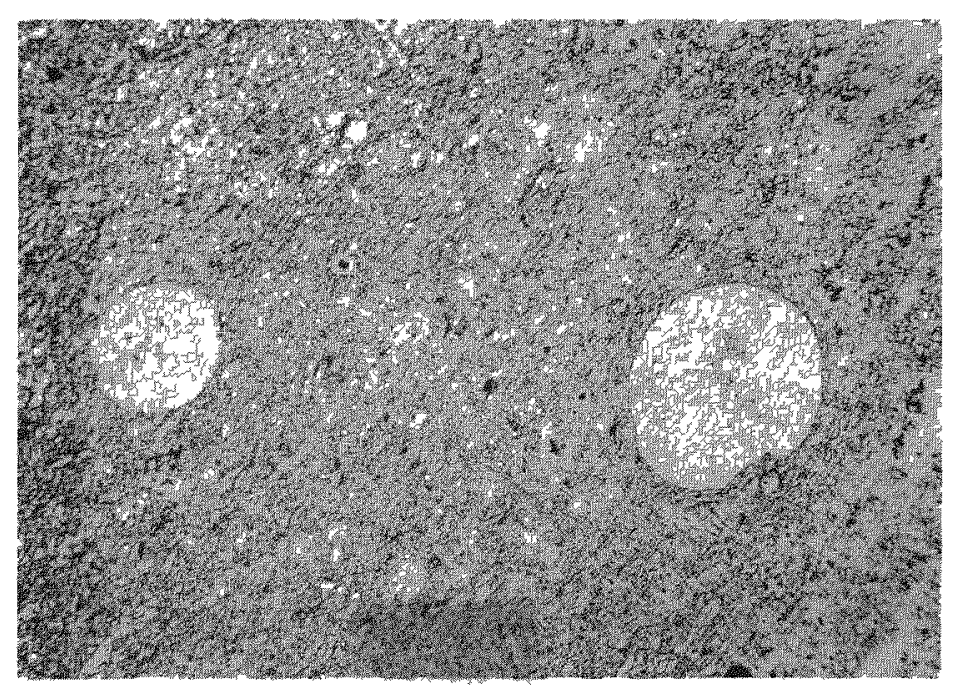

Plate 3869

Fig. 7

Uranium powder particles formed by atomization, mixed with fine urenium poither made by the hyarlae method, hot presste at $25 \mathrm{tsi}, 550^{\circ} \mathrm{C}$ 1 for 15 minutes in vacuum : 